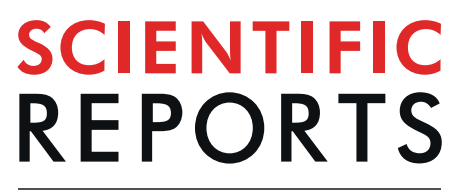

natureresearch

There are amendments to this paper

\title{
Analysis of Annual and Seasonal Precipitation Variation in the Qinba Mountain area, China
}

\begin{abstract}
Yannan Zhang \& Chuan Liang*
In this study, the spatial and temporal characteristics in precipitation extremes, total precipitation, and the seasonality of precipitation of the Qinba Mountain in China were investigated from 1961 to 2015, based on daily precipitation data of 37 meteorological stations. The results from our study suggest that: the annual precipitation in the area varies between $645 \mathrm{~mm}$ and $2175.2 \mathrm{~mm}$, with the minimum annual precipitation occurred in 1997, and the maximum annual precipitation, in 1963. Between 1961 and 2015, a significant decreasing trend was observed in the annual precipitation, suggesting a decrease of $-21.1 \mathrm{~mm} / \mathrm{a}$. The spatial distribution of precipitation in the Qinba Mountain area increased from the north to the south, showing an obvious difference in precipitation between the two areas. For extreme indices, the trends of annual total wet-day precipitation (PRCPTOT), number of heavy precipitation days (R10mm)and consecutive wet days (CWD)showed a downward trend, while the other extreme indices had an upward trend. The results from our research not only help the researchers to understand the characteristics of precipitation, but also provide crucial information for the policy makers to make better decisions, in future.
\end{abstract}

Global warming has made great changes in the regional atmospheric circulation and the water circulation, resulting in redistribution of precipitation around the world ${ }^{1}$. The latter has led to an increase in the number of natural disaster. During the last decades, the climate change has attracted widespread attention in the globalisation of society ${ }^{2}$. The precipitation pattern change is one of the main factors of the regional climate change, and can be also considered as a key factor in the economic development and the environmental change ${ }^{3}$. The change in precipitation pattern can cause catastrophic event and affect environment and society by increasing the probability of flooding in the area in time of heavy precipitation, or water deficiency as a result of the decrease in precipitation. Indeed, both floods and droughts can cause different levels of disasters. Therefore, it is important to study the effects of changes in precipitation characteristics on the ecology, environment, and economy of the area ${ }^{4}$.

China is a large population and agriculture is a vital industry in the country. Therefore, studying the changing trend of the precipitation is of great significance to the regional agricultural development and water resources allocation $^{5,6}$. During the recent decades, the total annual precipitation has slightly changed, in China and the spatial distribution of precipitation is very different in different areas within the China ${ }^{7}$. In the southwest, an increase in precipitation was observed both in the summer and the winter ${ }^{8}$. However, in the eastern region, significant seasonal variations in precipitation are recorded ${ }^{9}$. In the Yellow River Basin, the annual precipitation decreased significantly, in contrast, a significant increase was observed in the Yangtze River Valley ${ }^{10}$.

Mountainous area is a remarkable feature of the Chinese topography, which accounts for $2 / 3$ of the total area of the country. In the vast mountainous area with the inconvenient transportation, the development of regional agriculture lags behind ${ }^{11}$. At present, the economy of mountain areas mainly depends on the forest products, the mineral resources, the water power and the tourism resources. Therefore, the climate and rainfall change in the mountain areas have a direct impact on the economy of mountain areas ${ }^{12}$. The current literature reviews suggest that many studies have been carried out on the precipitation in mountain areas. Naresh Kumar Ashok et al. (2016) studied the temporal variation in the precipitation, considering the influence of the Western Himalayan Region, from 1857 to $2004^{13}$; Kexin Zhang et al. (2014) explored the spatial distribution and the temporal trends of the extreme precipitation in the Hengduan Mountains region, from 1961 to 2012. They suggested regional differences in regards with the influence of topography in the Hengduan Mountains region ${ }^{14}$. Junfeng Liu et al. (2016) studied the precipitation in the Qilian Mountains ${ }^{15}$. The precipitation changes of the Altai Mountains was subjected to 


\begin{tabular}{|l|l|l|}
\hline Month & Precipitation $(\mathbf{m m})$ & $\begin{array}{l}\text { Ratio of Annual } \\
\text { Precipitation } \mathbf{\%})\end{array}$ \\
\hline January & 42.6 & 4.1 \\
\hline February & 36.5 & 3.51 \\
\hline March & 56.5 & 5.44 \\
\hline April & 78.7 & 7.57 \\
\hline May & 106.3 & 10.23 \\
\hline June & 106.4 & 10.23 \\
\hline July & 152.1 & 14.64 \\
\hline August & 124.2 & 11.95 \\
\hline September & 122.1 & 11.75 \\
\hline October & 87.8 & 8.45 \\
\hline November & 71.4 & 6.87 \\
\hline December & 54.4 & 5.24 \\
\hline Annual & 1039 & 100 \\
\hline
\end{tabular}

Table 1. The precipitation amount in each month in the study area, during 1961-2015.

study by Malygina Natalia et al. and the influence of atmospheric circulations during 1959 to 2014 on the precipitation pattern was explored in depth ${ }^{16}$. Nina K Kononova et al. studied the effects of atmospheric circulation on the summertime precipitation variability, in Tianshan Mountains ${ }^{17}$.

Qinba Mountain area as a typical mountain area with limited access to the land is a national poverty area, which lies in a heavy rain zone. The area has a complex terrain, and suffers from floods, landslides, and other natural disasters such as mudslides ${ }^{18}$. Due to high intensity rainfall during a short period of time, slope mud is formed the stone flow and landslide, which cause serious disasters and losses ${ }^{19}$. It is now widely recognized that the extreme events are very likely to increase, as a result of the climate change. Such a catastrophic events have much greater impacts on the environment and the society, than a small shift in the mean values ${ }^{20}$.

The precipitation around the Qinba Mountain area has been redistributed under the influence of the global warming, during recent years ${ }^{21,22}$. Hence, the aim of this research is to study the temporal and spatial characteristics of the precipitation in the Qinba Mountain area, and to provide a reference for predicting the occurrence of extreme precipitation ${ }^{23}$.

The precipitation data from 37 stations were selected in Qinba Mountain and surrounding areas. The homogeneity of these data was tested and the data quality was significantly improved after correction. Subsequently, temporal changes in the annual and seasonal precipitation during 1961 to 2015, as well as the trend of eight extreme precipitation indices and distributions of the temporal change in precipitation were examined in this work. The outcome from this research can be served as a reference for the researchers in this area and provides sufficient information for the policy makers in fields of agriculture and water resource management.

\section{Results}

Temporal trends of precipitation change. Based on the daily precipitation data between 1961 and 2015, the monthly mean precipitation is calculated in order to study the monthly precipitation distribution. During 1961-2015, the annual mean precipitation in the study area was $1039 \mathrm{~mm}$ (Table 1). Among the four seasons, the precipitation during the summer (June- August), and the autumn (September- November) accounts for 35.1\% and $24.2 \%$ of the annual precipitation, respectively. Therefore, the precipitation in the QM is mainly concentrated in the summer, and July has the most precipitation with the ratio of $14.64 \%$ of the annual precipitation, and February has the least precipitation with the ratio of $3.51 \%$.

The trends of the annual and the seasonal precipitation were examined using the moving average and linear regression methods. Figure 1 shows the change of annual and seasonal precipitation in the QM. As it can be observed in the figure, the annual precipitation fluctuated between $645 \mathrm{~mm}$ and $2175.2 \mathrm{~mm}(1961-2015)$, with the minimum and the maximum annual precipitation in 1997 and 1963, respectively. The annual precipitation trend is $-21.1 \mathrm{~mm} / \mathrm{a}$ in the area and the seasonal precipitation trends in the spring, the summer, the autumn, and the winter are $-2.45 \mathrm{~mm} / \mathrm{a},-2.65 \mathrm{~mm} / \mathrm{a},-9.32 \mathrm{~mm} / \mathrm{a}$ and $-6.71 \mathrm{~mm} / \mathrm{a}$, respectively (Fig. 1 ). The annual precipitation and the seasonal precipitation suggest a downward trend. The trend of annual precipitation and the seasonal precipitation are significant at $95 \%$ confidence level.

Trends in extreme precipitation indices. Table 2 presents the trend and the Mann-Kendall (MK) test of the eight extreme precipitation indices ${ }^{24}$. For the entire study area, SDII, RX1day, RX5day and R95p displayed an increasing trend between 1961 and 2015. However, only the regional trend of the SDII passed the significance test at the $5 \%$ significance level. The trend of SDII is $0.024 \mathrm{~mm} /$ day/ decade in study area, and SDII had a regionally positive trend at $88.2 \%$ of the stations. A decreasing trend was identified in PRCPTOT, in the study area with a value of $-1.86 \mathrm{~mm} /$ decade. The trend failed the significance test at the $5 \%$ significance level, suggesting that the precipitation in the region shows an insignificant trend. $\mathrm{R} 10 \mathrm{~mm}$ displayed decreasing trend with a value of $-0.006 \mathrm{~d} /$ decade, at $94 \%$ of the stations. Consecutive wet days (CWD) is an index to measure the extreme of consecutive wet days. The CWD showed a decreasing trend with a value of -0.02 day/decade. Corresponding with the CWD, consecutive dry days (CDD) is an index to measure extreme of consecutive dry days. Based on the $\mathrm{CDD}$, the regional trend was $0.14 \mathrm{~d} /$ decade for the study area. 
a
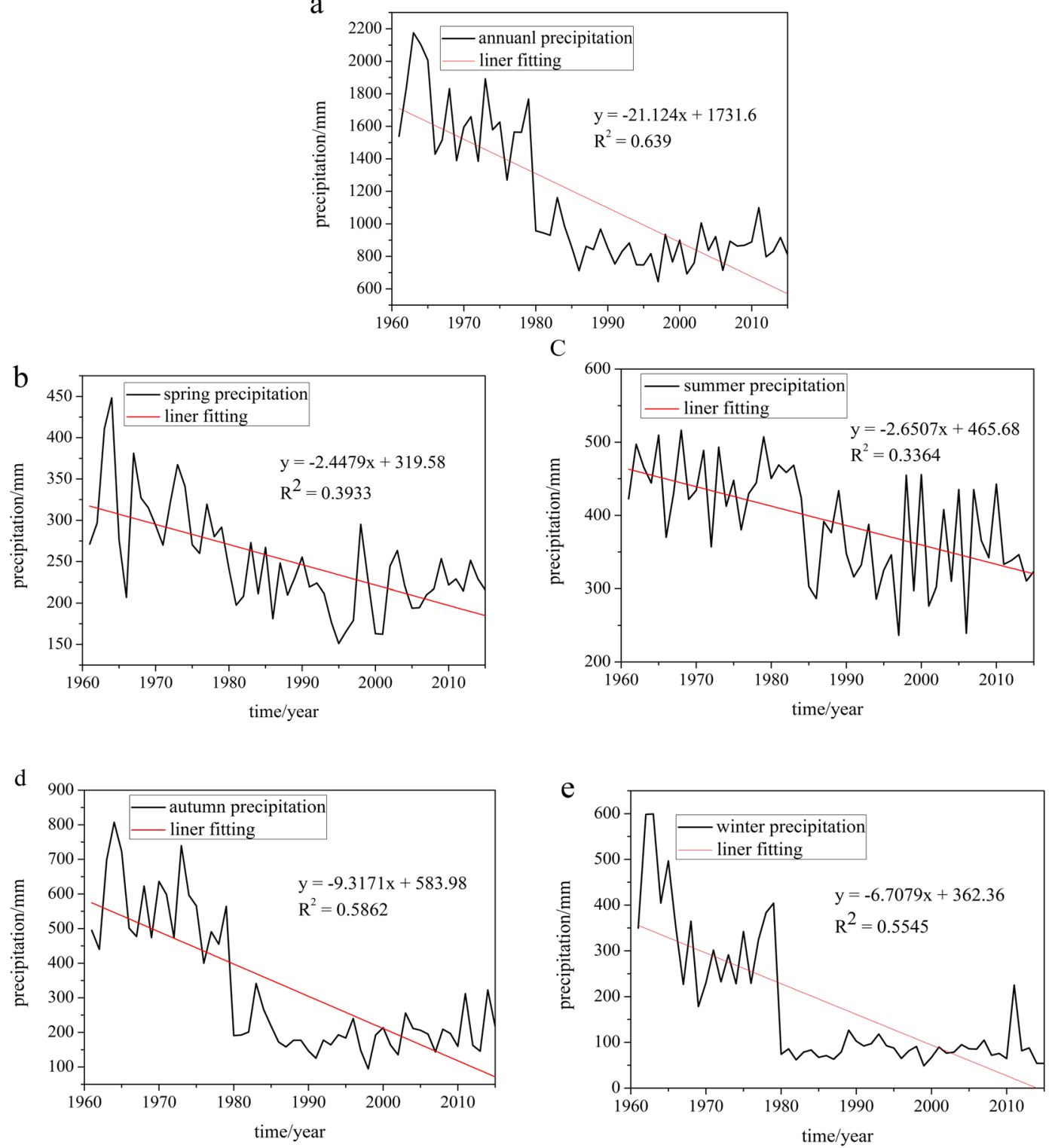

Figure 1. Change trends of the annual and the seasonal precipitation in the Qinba mountain area: (a) annual, (b) spring, (c) summer, (d) autumn, and (e) winter.

\begin{tabular}{|c|c|c|c|c|c|c|c|c|}
\hline \multirow[b]{2}{*}{ Index } & \multicolumn{2}{|l|}{ Regional Trends } & \multicolumn{2}{|l|}{ MK Test } & \multirow{2}{*}{$\begin{array}{l}\text { Percentage of Stations } \\
\text { with Positive Trend }\end{array}$} & \multirow{2}{*}{$\begin{array}{l}\text { Percentage of Stations with } \\
\text { Significant Positive Trend }\end{array}$} & \multirow{2}{*}{$\begin{array}{l}\text { Percentage of } \\
\text { Stations with } \\
\text { Negative Trend }\end{array}$} & \multirow{2}{*}{$\begin{array}{l}\text { Percentage of Stations } \\
\text { with Significant } \\
\text { Negative Trend }\end{array}$} \\
\hline & Units & L & $\mathrm{z}$ & p-Value & & & & \\
\hline PRCPTOT & $\mathrm{mm} /$ decade & -1.8601 & -1.7568 & 0.078 & $23.5 \%$ & 0 & $76.5 \%$ & $6 \%$ \\
\hline SDII & $\mathrm{mm} /$ day/decade & 0.0237 & 2.0399 & 0.041 & $88.2 \%$ & 0 & $11.8 \%$ & 0 \\
\hline RX1day & $\mathrm{mm} /$ decade & 0.0609 & 0.5735 & 0.569 & $35.3 \%$ & 0 & $64.7 \%$ & 0 \\
\hline RX5day & $\mathrm{mm} /$ decade & 0.0246 & 0.087 & 0.928 & $53 \%$ & 0 & $47 \%$ & 0 \\
\hline R95p & $\mathrm{mm} /$ decade & 0.7046 & 1.6116 & 0.107 & $100 \%$ & $6 \%$ & 0 & 0 \\
\hline R10mm & days/decade & -0.0065 & -0.1742 & 0.865 & $6 \%$ & 0 & $94 \%$ & $18 \%$ \\
\hline $\mathrm{CDD}$ & days/decade & 0.1412 & 1.3575 & 0.174 & $76.5 \%$ & 0 & $23.5 \%$ & 0 \\
\hline CWD & days/decade & -0.0168 & -1.8584 & 0.063 & $23.5 \%$ & 0 & $76.5 \%$ & 0 \\
\hline
\end{tabular}

Table 2. The results of regional trends and the Mann-Kendall (MK) test for the extreme precipitation indices over the QM during 1961-2015. Notes: L denotes linear trends (decade ${ }^{-1}$ ), $\mathrm{Z}$ is the standardized MK test statistic. Values for statistically significant trends at a 5\% significant level are in bold. 

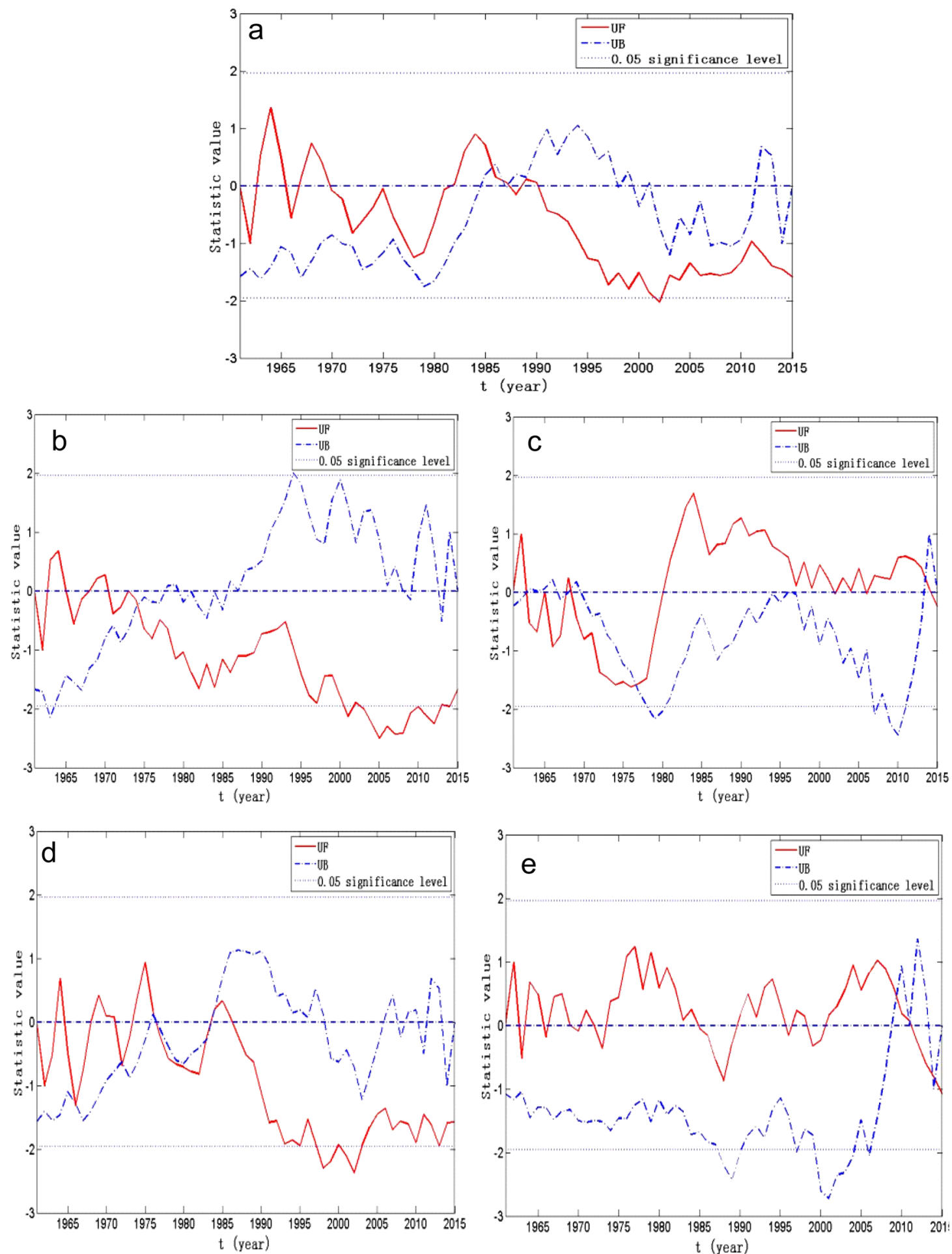

Figure 2. Mann-Kendall statistic curve of the annual and the seasonal precipitation sequence: (a) annual, (b) spring, (c) summer, (d) autumn, and (e) winter.

A downward trend was identified in PRCPTOT and R10 mm, while the SDII, RX1day, RX5day and R95p had an upward trend. At the same time, a decrease in the CDD and an increase in the CWD, which implied the possibility of increase of the extreme rainfall.

Abrupt changes of annual and seasonal precipitation. Detecting the precipitation change point is an essential factor that can help to provide a better interpretation and more accurate forecast for the hydrological data. The change points of the annual and seasonal precipitation time series are presented in Fig. 2. Abrupt changes were observed in the inter-annual variation of the annual and seasonal precipitation in the study area. 


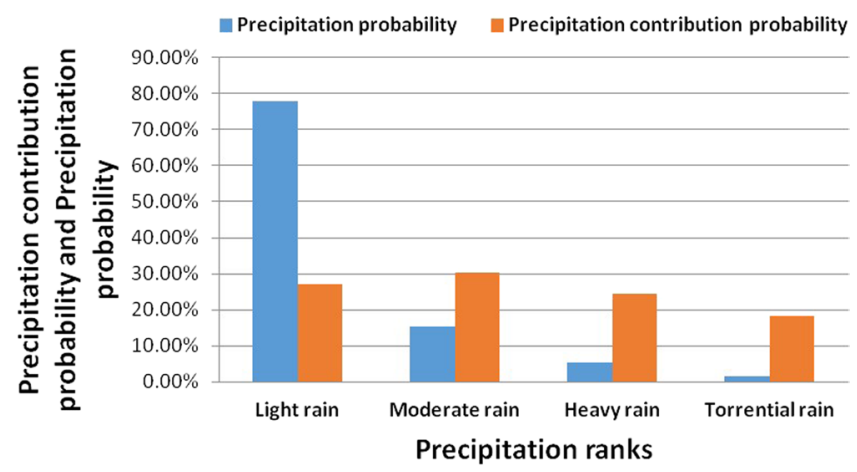

Figure 3. The incidence and contribution rates of different precipitation ranks in the Qinba Mountains.

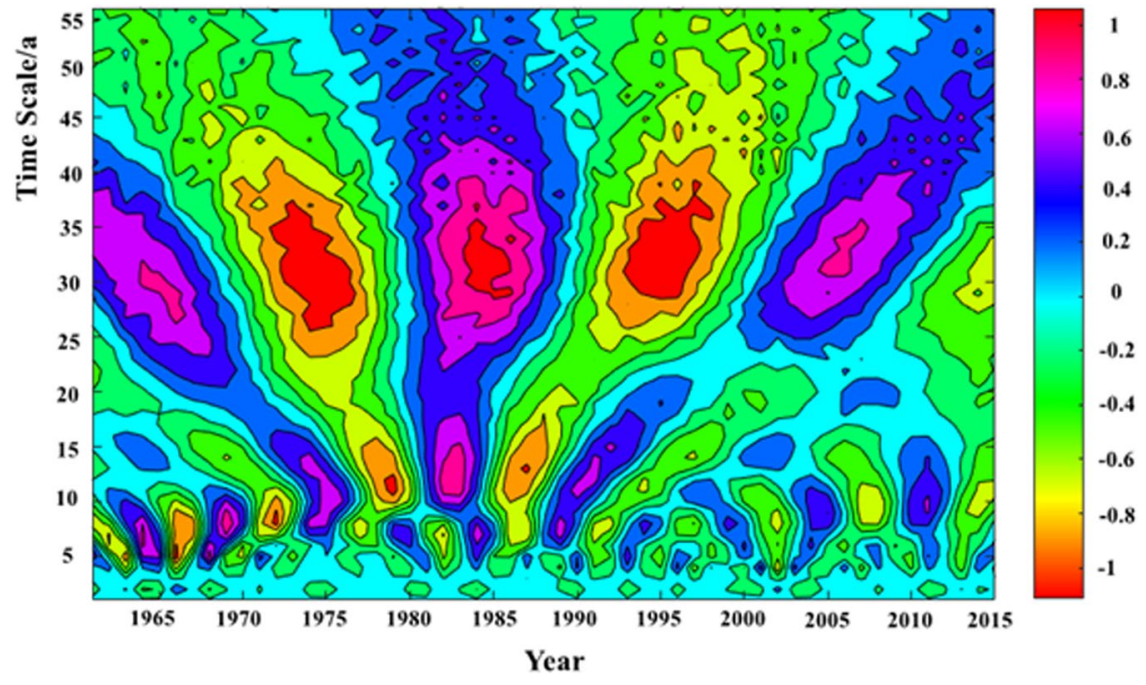

Figure 4. The annual precipitation Morlet wavelet transform in the study area.

Figure 2(a) represents the obvious intersection occurred in 1986, suggesting a sudden decrease in the annual precipitation, after 1986. Figure 2(b) suggests the presence of an obvious intersection in spring precipitation, which occurred in 1973, followed by a significant spring precipitation decrease, between 2000 and $2013(P<0.05)$. Figure 2(c) represents obvious intersections in summer precipitation, with the intersections in 1963, 1967, 1970, and 1977. The summer precipitation showed an increasing trend, after 1977. Figure 2(d) displays the obvious intersections in autumn precipitation, with the intersections in 1967, 1972, 1976, 1983, and 1984. The autumn precipitation pattern started to show a decreasing trend after 1984, with a significant decrease from 1998 to $2002(P<0.05)$. The obvious intersection in winter precipitation, occurred in 2008, can be detected in Fig. 2(e) followed by a decrease after 2008. According to the above analyses, only certain degree of abrupt changes of the annual and seasonal precipitation can be identified in the study area.

Precipitation ranks analysis. Figure 3 represents the statistical results of the incidence and contribution rates of different precipitation ranks in the Qinba Mountains. As it can be seen in the figure, the increase of precipitation grade resulted in a decrease in the probability of precipitation. The probability of the light rain, the moderate rain, the heavy rain, and the torrential rain are $77.94 \%, 15.32 \%, 5.35 \%$, and $1.39 \%$, respectively. The probability of light rain is dominant in the area. In terms of different levels of precipitation contribution rate, the contribution rates of the light rain, the moderate rain, the heavy rain, and the torrential rain are $26.95 \%, 30.4 \%$, $24.34 \%$, and $18.31 \%$, respectively.

Morlet wavelet analysis. The real-data contour map of the annual precipitation Morlet wavelet transform in the Qinba Mountain area, is presented in Fig. 4. Based on the contour map, the annual precipitation has an inter-decadal variation period of 30a 35a on the whole time scale. The central scale is $32 \mathrm{a}$, and the periodic oscillation is very significant. Short periods of $5 \mathrm{a} \sim 10 \mathrm{a}$ are also detected on the inter-annual scale, with the central scale of $8 \mathrm{a}$. The scale period is more obvious during the 1960s to 1970s. In addition, short-period oscillations of $10 \mathrm{a} \sim 15 \mathrm{a}$ are existed on a small scale, before 1990s, and the period remains unclear, after 1990s. 


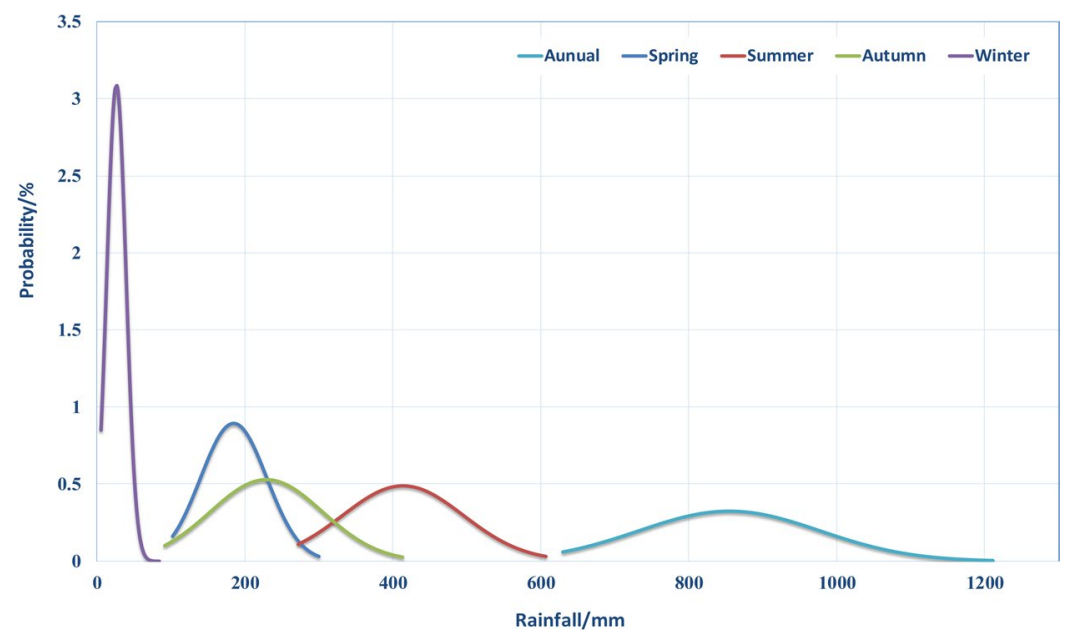

Figure 5. The probability density function (PDF) of the annual and the seasonal precipitation sequences in the Qinba Mountains.

The probability density function (PDF). The probability density function (PDF) was used to analyse the annual and seasonal precipitation sequences in the study area. The presented results in Fig. 5 suggest that the precipitation in the Qinba Mountain area accords with the Gaussian normal probability distribution. Furthermore, the PDF curves of the annual precipitation and the seasonal precipitation are bimodal, while, the PDF curve of the winter precipitation is identified as the steepest and the highest peak, and located close to the horizontal and vertical coordinates. This indicates that the winter precipitation distribution is mainly concentrated in the light rain range, and the probability of its occurrence is small.

Spatial variation. Figure 6 represents the spatial distribution of precipitation in Qinba Mountain Area. Figure 6(a) shows that the spatial distribution of precipitation between the north and the south is obviously different and it decreases from the south to the north. The areas with the high rate of precipitation are mainly concentrated in the southwest of the study area, and the areas with the lowest rate of precipitation appear in the northwest of the Qinba Mountain Area. Generally speaking, the annual precipitation in most of the region in the study area presents a decreasing pattern (Fig. 6b). The increasing trend of the precipitation are observed in the central and the northeast part of the QM, indicating that flooding may occur in these areas. In contrast the decreasing trend appears in the western, the eastern, and the southern regions of the QM, suggesting the probability of drought occurrence in these areas. Figure 6(c) represents uneven distribution of the PRCPTOT in the study area, with the highest concentration in the southwest. Figure 6(d) shows that the SDII of the central region is fluctuating between 9 and 15, and the largest value of the SDII are observed in Wanyuan, Bazhong, Guangyuan, and Fengjie, fluctuating between 12 and 15. Figure 6(e) shows that the highest rate of the CWD is observed in the central and surrounding areas of the study area, with a value between 6 and 8 . The highest rate of the CDD occurs in the central and the western parts of the study area, with more concentration in the western region (Fig. 6(f)). Figure 6(g) suggests the areas with R10 are mainly located in the central and the surrounding areas of the study area. Based on these information, floods are likely to occur in the central part of the study area.

The relationship between precipitation and altitude, latitude and longitude. The spatial distribution of the precipitation in the study area also varies greatly in different areas and the precipitation is correlated to the latitude, the longitude, and the altitude to a certain extent ${ }^{25}$. As it can be observed in Fig. 7 the precipitation decreases with the increase in the longitude, the latitude, and the altitude, and the amount of precipitation decreases significantly with the increase of the latitude. Based on the Table 3 , the correlation coefficient $\mathrm{R}$ between the precipitation and the latitude is -0.804 and it is highly significant at $99 \%$ level. The correlation coefficient $\mathrm{R}$ of the precipitation and the longitude is -0.075 and it is very insignificant, with no obvious relationship between the precipitation and the longitude. Furthermore, an insignificant correlation coefficient $\mathrm{R}$ is present between the precipitation and the altitude, which is -0.307 . Therefore, it can be concluded that the precipitation is mainly related to the latitudinal zonation in the study area.

\section{Discussion}

Based on the current literature ${ }^{26,27}$, a downward trend was observed in the national precipitation, after 1980, and the annual precipitation showed a downward trend in the northeast and the northwest of China. R10mm and the CWD all showed a downward trend in the Yangtze River Basin ${ }^{6,7}$, while the CDD showed an upward trend, especially as the SDII, the RX1day, the RX5day, and the R95p also showed an upward trend. The results from our study are basically consistent with the previous results, however, the mutation points of precipitation changes in various regions are different.

The annual precipitation gradually decreases from the south to the north, which is in agreement with the spatial of precipitation, in China ${ }^{28}$. The maximum SDII and positive trends of precipitation are observed in the central and the northeast part of study area. The CWD and the R10 are more in the central part of the study area. 

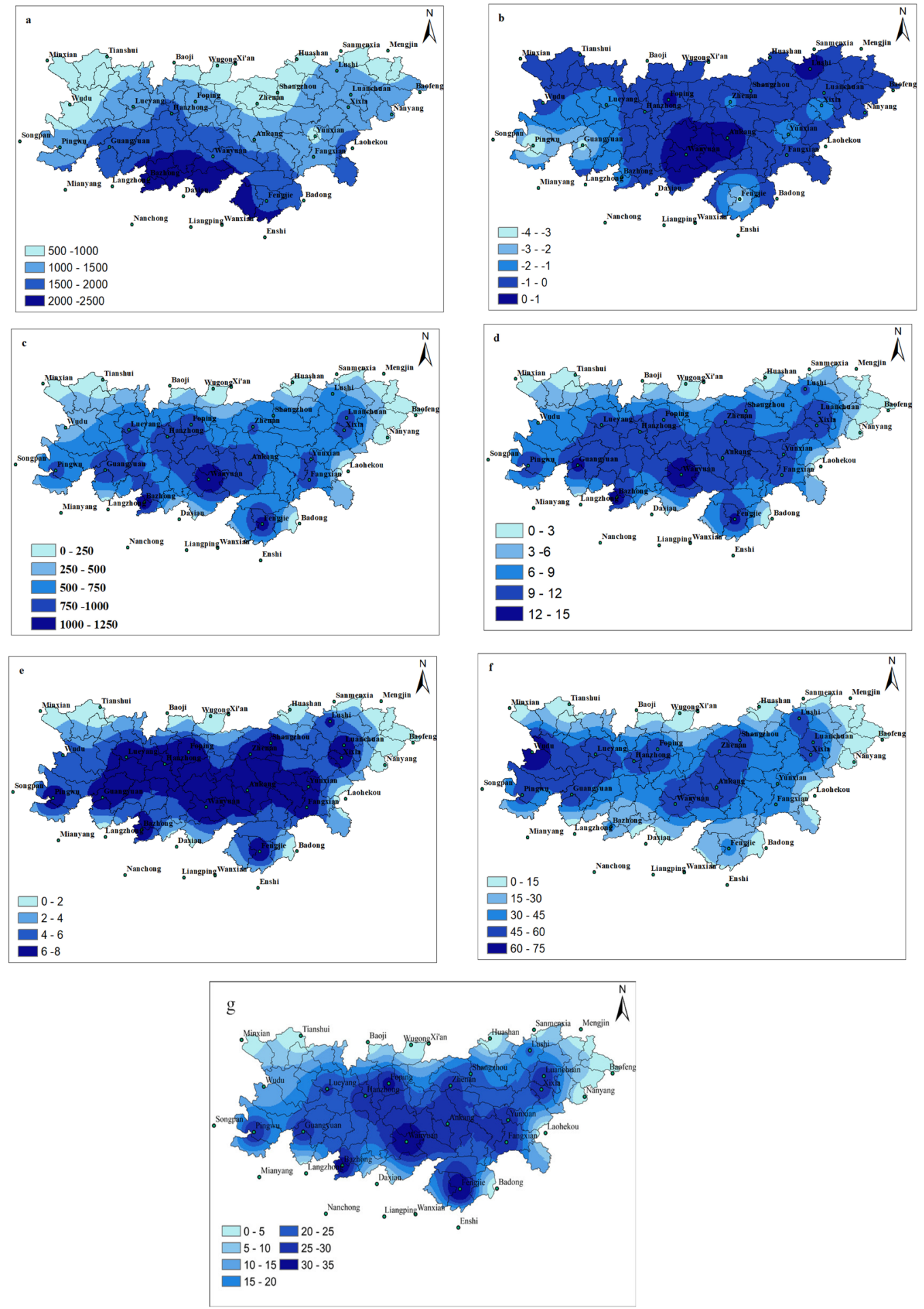

Figure 6. Spatial distribution patterns of the annual precipitation and extreme precipitation indices: (a) Annual precipitation, (b) Trends in annual precipitation change, (c) Annual total wet-day precipitation (PRCPTOT), (d) Simple daily intensity index (SDII), (e) Consecutive wet day (CWD), (f) Consecutive dry days (CDD), (g) Number of heavy precipitation days (R10). The maps are generated with Arc Map version 10.1 (http://www.esri. com/software/arcgis).

Meanwhile, the negative trends appear in the western and the southern regions of the study area, with a higher rate of CDD in the central and the western regions of the study area. On this basis, extreme precipitation is likely to occur in the central region, which may lead to either the regional floods, or the regional droughts. 

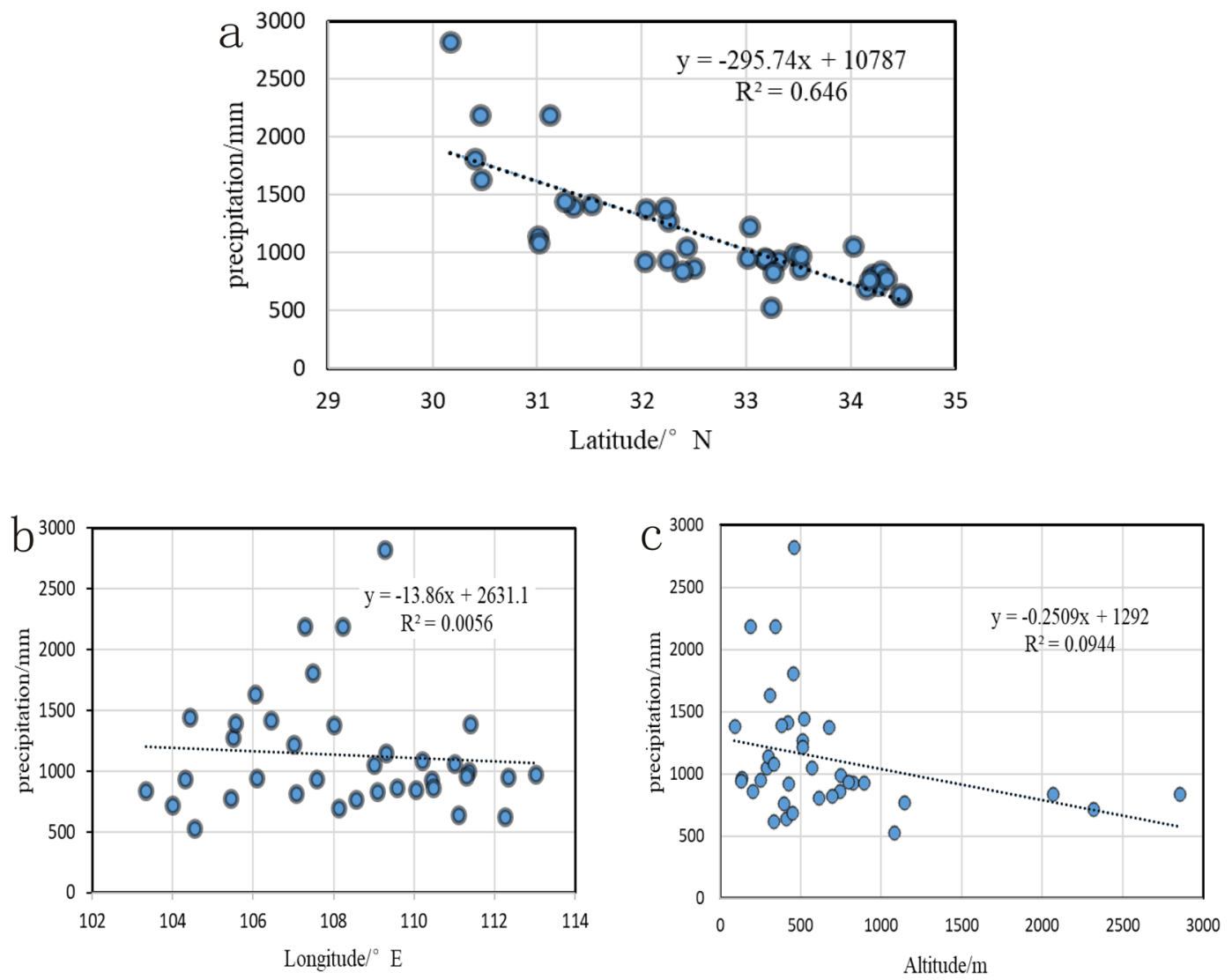

Figure 7. The relationship between the precipitation and the longitude, the latitude, and the altitude.

\begin{tabular}{|l|l|l|l|l|}
\hline & precipitation & latitude & longitude & altitude \\
\hline precipitation & 1 & $-0.804 * *$ & -0.075 & -0.307 \\
\hline
\end{tabular}

Table 3. The correlation coefficients between the precipitation and the longitude, the latitude, and the altitude. **Denotes Significant at the 0.01 level.

Atmospheric circulation changes are considered as important mechanisms, which affect the regional heat and water transport ${ }^{29}$. Due to the location of the study area, which is located in the eastern part of the Qinghai-Tibet Plateau and in the central part of the Yangtze River Basin, the precipitation changes are largely affected by the monsoon climate. The monsoon climate change in the Yangtze River Basin can determine the amount of precipitation, to a certain extent. Yang Bo et al. (2014) suggested that the extreme precipitation events in the Qinba Mountain area may be affected by the southwest monsoon, which has a great influence on the climate of the surrounding $\operatorname{area}^{30}$. El Niño-Southern Oscillation(ENSO)has certain influence on the precipitation changes during the different seasons ${ }^{31}$. At the same time, the influence of topography on the precipitation distribution and extreme precipitation variation is deniable ${ }^{32}$. Indeed, due to the special geographical location of the study area and the type of landforms in the mountainous hills, the types of climate are diverse, and the deriving factors which affect the precipitation change remain unclear. The latter explains the necessity of conducting further study to identify the impact of extreme precipitation on climate change and its future trends.

\section{Conclusions}

The main finding of this study are as follows:

1. In general, the annual precipitation and the seasonal precipitation showed a downward trend, and the annual precipitation decreased after 1986. The annual precipitation suggested an inter-decadal variation period of 30a 35a on the whole time scale, with a significant periodic oscillation. The increase in the precipitation rank resulted in decrease of the incidence of precipitation.

2. Only the Regional trend of the SDII passed the significance test at the $5 \%$ significance level, among the eight precipitation extreme indices. The SDII, the RX1day, the RX5day, and the R95p displayed an increasing trend, while the PRCPTOT displayed a decreasing trend, during 1961-2015. Analysing the relationship between the precipitation and the longitude, the latitude, and the altitude, we identified that the precipitation is greatly related to latitudinal zonation, in the study area.

3. The uneven spatial distribution of precipitation in the study area suggests a higher rate of the annual 


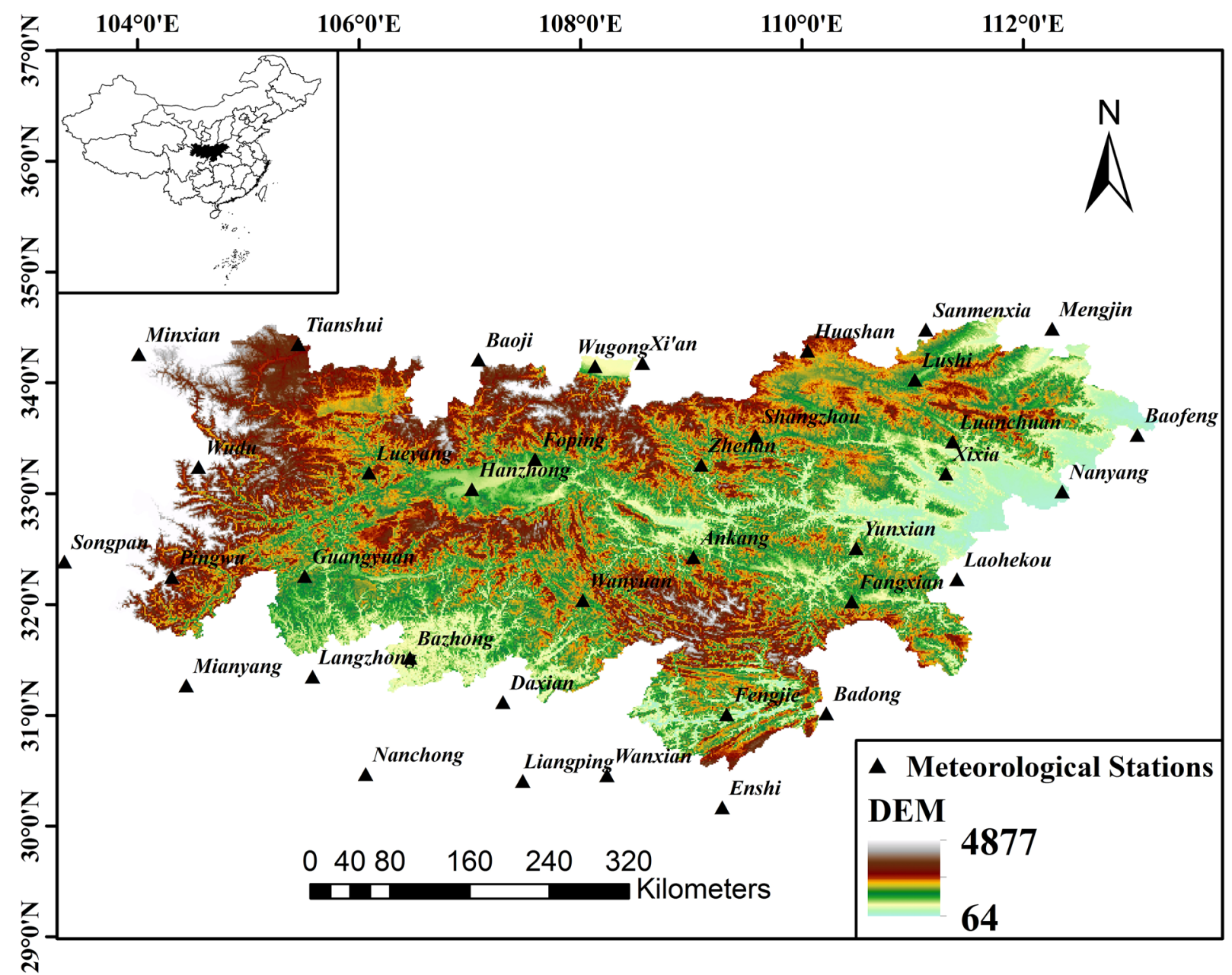

Figure 8. Distribution of weather stations in the region. The maps are generated with Arc Map version 10.1 (http://www.esri.com/software/arcgis).

precipitation in the central and the southwest regions, in comparison with the other regions. The areas with the CWD and R10 are mainly located in the central and the surrounding areas of the study area, while the areas with CDD are mainly existed in the central and the western parts of the study area.

To conclude, this research studied the temporal and spatial variation characteristics of precipitation in the area, based on the meteorological data. The results from this study can reflect the overall precipitation changes in the region. Due to the limited selection of the meteorological data, the precipitation changes in some areas are not necessarily accurately reflected. The regional runoff changes and the high-precision precipitation data can more accurately reflect the regional floods and the drought conditions, which can be subjected to study, in future.

Study area. Qinba Mountain is located in the central China, between $102^{\circ} 54^{\prime} \mathrm{E} \sim 113^{\circ} 40^{\prime} \mathrm{E}$ and $30^{\circ} 50^{\prime} \mathrm{N} \sim$ $34^{\circ} 59^{\prime} \mathrm{N}$, with a total area of $225,000 \mathrm{~km}^{2}$. It sits east of the Qinghai-Tibet Plateau, and the landforms are dominated by the mountains. The Qinba Mountain area is an important ecological barrier in the upper reaches of the Yangtze River. The forests, the grass resources, the regional products, and the mineral resources are extremely rich. The area is not only the main grain-producing land, but also rich in dozens of regional products such as silk, ramie, tea, lacquer. The Qinba Mountain area is also very rich in the underground treasures, and is considered as an important non-ferrous metal and precious metal deposit area, in China.

Data. In this study, the daily precipitation data from 1961 to 2015 were selected from 37 sites (including 17 sites in the study area) with long, uniform, and representative precipitation in Qinba and surrounding areas (Fig. 8). Meteorological data were collected from the China Meteorological Data Sharing Service Network (http:// data.cma.cn/), and data quality control was performed by mean of the RClimDex software. Missing data from the Meteorological Stations were interpolated using the Kriging interpolation. Missing data of one day or two days were filled by average values of the neighbouring days. If consecutive days had missing data, the missing values were replaced with the long-term averages of the same days ${ }^{33,34}$.

The meteorological station's detailed information are presented in Table 4 . The selected stations are spread out over the study area, unevenly. The seasons were define as follows: the winter (December, January, and February), 


\begin{tabular}{|c|c|c|c|c|}
\hline $\begin{array}{l}\text { Station } \\
\text { number }\end{array}$ & Name & Latitude $\left({ }^{\circ} \mathrm{N}\right)$ & Longitude $\left({ }^{\circ} \mathrm{E}\right)$ & Altitude(m) \\
\hline 57245 & Ankang & 32.43 & 109.02 & 290.8 \\
\hline 57313 & Bazhong & 31.52 & 106.46 & 417.7 \\
\hline 57259 & Fangxian & 32.03 & 110.45 & 426.9 \\
\hline 57348 & Fengjie & 31.01 & 109.32 & 299.8 \\
\hline 57134 & Foping & 33.31 & 107.59 & 827.2 \\
\hline 57206 & Guangyuan & 32.26 & 105.51 & 513.8 \\
\hline 57127 & Hanzhong & 33.04 & 107.02 & 509.5 \\
\hline 57067 & Lushi & 34.03 & 111.02 & 568.8 \\
\hline 57077 & Luanchuan & 33.47 & 111.36 & 750.3 \\
\hline 57106 & Lueyang & 33.19 & 106.09 & 794.2 \\
\hline 56193 & Pingwu & 32.25 & 104.31 & 893.2 \\
\hline 57143 & Shangzhou & 33.52 & 109.58 & 742.2 \\
\hline 57237 & Wanyuan & 32.04 & 108.02 & 674 \\
\hline 56096 & Wudu & 33.24 & 104.55 & 1079.1 \\
\hline 57156 & Xixia & 33.18 & 111.3 & 250.3 \\
\hline 57253 & Yunxian & 32.51 & 110.49 & 201.9 \\
\hline 57144 & Zhenan & 33.26 & 109.09 & 693.7 \\
\hline 57355 & Badong & 31.02 & 110.22 & 334 \\
\hline 57181 & Baofeng & 33.53 & 113.03 & 136.4 \\
\hline 57016 & Baoji & 34.21 & 107.08 & 612.4 \\
\hline 57328 & Daxian & 31.12 & 107.3 & 344.9 \\
\hline 57447 & Enshi & 30.17 & 109.28 & 457.1 \\
\hline 57046 & Huashan & 34.29 & 110.05 & 2064.9 \\
\hline 57306 & Langzhong & 31.35 & 105.58 & 382.6 \\
\hline 57265 & Laohekou & 32.23 & 111.4 & 90 \\
\hline 57426 & Liangping & 30.41 & 107.48 & 454.5 \\
\hline 57071 & Mengjin & 34.49 & 112.26 & 333.3 \\
\hline 56196 & Mianyang & 31.27 & 104.44 & 522.7 \\
\hline 56093 & Minxian & 34.26 & 104.01 & 2315 \\
\hline 57411 & Nanchong & 30.47 & 106.06 & 309.7 \\
\hline 57178 & Nanyang & 33.02 & 112.35 & 129.2 \\
\hline 57051 & Sanmenxia & 34.48 & 111.12 & 409.9 \\
\hline 56182 & Songpan & 32.39 & 103.34 & 2850.7 \\
\hline 57006 & Tianshui & 34.35 & 105.45 & 1141.7 \\
\hline 57432 & Wanxian & 30.46 & 108.24 & 186.7 \\
\hline 57034 & Wugong & 34.15 & 108.13 & 447.8 \\
\hline 57036 & Xi'an & 34.18 & 108.56 & 397.5 \\
\hline
\end{tabular}

Table 4. Detailed information of the selected stations.

the spring (March, April, and May), the summer (June, July, and August), and the autumn (September, October, and November).

Consequently, the annual precipitation, the monthly precipitation, the seasonal precipitation, and the eight precipitation extreme indices were discussed in this study. The related concepts of precipitation extreme indices are presented in Table $5^{35}$.

\section{Methods}

Linear regression method. The linear regression method is employed to investigate and analyse the longterm trends of the precipitation, in the time series. The main statistical parameter (i.e. the slope) is used to indicate the temporal change of the studied variable on the spatial scale. This method intuitively reflects the trend of the rainfall time series, and the slope of the linear equation represents the average change rate of the trend (unit: $\mathrm{mm} / \mathrm{y}$ ). The slope can be calculated using the Eq. (1), as follows:

$$
\text { Slope }=\frac{\mathrm{n} \times \sum_{\mathrm{i}=1}^{\mathrm{n}}\left(\mathrm{i} \times \mathrm{p}_{\mathrm{i}}\right)-\sum_{\mathrm{i}=1}^{\mathrm{n}} \mathrm{i} \sum_{\mathrm{i}=1}^{\mathrm{n}} \mathrm{p}_{\mathrm{i}}}{\mathrm{n} \times \sum_{\mathrm{i}=1}^{\mathrm{n}} \mathrm{i}^{2}-\left(\sum_{\mathrm{i}=1}^{\mathrm{n}}\right)^{2}}
$$

where slope represents the estimated linear trend of precipitation during the period of 1961 to 2015 . The positive values of the slope indicate the increasing trend, while the negative values of the slope denote the decreasing trend; $i$ is the number of years in the time series (i.e. from 1 to 55 , in our study); and $p_{i}$ is the annual precipitation amount $^{36}$. 


\begin{tabular}{|l|l|l|l|}
\hline Index & Descriptive concept & Index Definitions & Units \\
\hline PRCPTOT & Annual total wet-day precipitation & Annual total precipitation $(\mathrm{PR} \geq 1 \mathrm{~mm})$ & $\mathrm{mm}$ \\
\hline RX1day & Maximum 1-day precipitation & Maximum 1-day precipitation & $\mathrm{mm}$ \\
\hline RX5day & Maximum 5-day precipitation & Maximum consecutive 5-day precipitation & $\mathrm{mm}$ \\
\hline R95p & Very wet day precipitation & Total precipitation $(\mathrm{PR}>95$ th percentile of days with PR $\geq 1 \mathrm{~mm})$ & $\mathrm{mm}$ \\
\hline R10mm & Number of heavy precipitation days & Annual count of days when PR $\geq 10 \mathrm{~mm}$ & days \\
\hline CDD & Consecutive dry days & Maximum number of consecutive days with PR $<1 \mathrm{~mm}$ & days \\
\hline CWD & Consecutive wet days & Maximum number of consecutive days with PR $\geq 1 \mathrm{~mm}$ & days \\
\hline SDII & Simple daily intensity index & Average daily precipitation when PR $\geq 1 \mathrm{~mm}$ & Mm/day \\
\hline
\end{tabular}

Table 5. The precipitation indices of the study.

Mann-kendall method. The Mann-Kendall method (M-K) has been widely used to assess trends in hydro-climatic data, Hence, we used this method to test the trends of precipitation in the study area.

The M-K method is a non-parametric method, and the World Meteorological Organization strongly recommends this method for analyses of the hydrological series, because this method does not require any distribution assumptions on the data ${ }^{37}$.

Mann-Kendall trend test is defined as follows:

$$
\mathrm{T}=\sum_{\mathrm{i}=1}^{\mathrm{m}-1} \sum_{\mathrm{j}=\mathrm{i}+1}^{\mathrm{m}} \operatorname{sgn}\left(\mathrm{x}_{\mathrm{i}}-\mathrm{x}_{\mathrm{j}}\right)
$$

Where $T$ is a value, $x_{i}$ and $x_{j}$ are the sequential precipitation data values, $m$ is the Number of time series, and sgn $\left(\mathrm{x}_{\mathrm{i}}-\mathrm{X}_{\mathrm{j}}\right)$ is expressed as follows:

$$
\operatorname{sgn}\left(\mathrm{x}_{\mathrm{i}}-\mathrm{x}_{\mathrm{j}}\right)= \begin{cases}1 & \text { if } \mathrm{x}_{\mathrm{i}}>\mathrm{x}_{\mathrm{j}} \\ 0 & \text { if } \mathrm{x}_{\mathrm{i}}=\mathrm{x}_{\mathrm{j}} \\ -1 & \text { if } \mathrm{x}_{\mathrm{i}}<\mathrm{x}_{\mathrm{j}}\end{cases}
$$

The variance of the $\mathrm{T}$ statistic is expressed as follows:

$$
\operatorname{Var}(\mathrm{T})=\frac{\mathrm{m}(\mathrm{m}-1)(2 \mathrm{~m}+5)}{18}
$$

And the test statistic $\mathrm{Z}$ is expressed as follows:

$$
\mathrm{Z}=\left\{\begin{array}{lll}
\frac{\mathrm{T}-1}{\sqrt{\operatorname{Var}(\mathrm{T})}} & \text { if } & \mathrm{T}>0 \\
0 & \text { if } & \mathrm{T}=0 \\
\frac{\mathrm{T}+1}{\sqrt{\operatorname{Var}(\mathrm{T})}} & \text { if } & \mathrm{T}<0
\end{array}\right.
$$

The $Z$ value is used to calculate the statistically significant trend. A positive value of $Z$ represents an upward trend, while a negative value of $Z$ suggests a downward trend. $Z_{\alpha} / 2$ is the critical value of the standard normal distribution. If $|\mathrm{Z}| \geq \mathrm{Z}_{\alpha / 2}$, the trend is significant, while $|\mathrm{Z}|<\mathrm{Z}_{\alpha / 2}$, represents an insignificant trend.

In this study, the $M-K$ test is used to detect whether a trend in the rainfall time series is statistically significant at a $95 \%$ confidence level. Mann-Kendall test can be further used to test sequence mutation, as follows:

$$
\mathrm{UF}_{\mathrm{K}}=\frac{\left|\mathrm{S}_{\mathrm{K}}-\mathrm{E}\left(\mathrm{S}_{\mathrm{K}}\right)\right|}{\sqrt{\operatorname{Var}\left(\mathrm{S}_{\mathrm{K}}\right)}}(k=1,2, \ldots, n)
$$

Where $\mathrm{E}\left(\mathrm{S}_{\mathrm{k}}\right)=\mathrm{k}(\mathrm{k}-1) / 4 ; \operatorname{Var}\left(\mathrm{S}_{\mathrm{k}}\right)=\mathrm{k}(\mathrm{k}-1)(2 \mathrm{k}+5) / 72$

$\mathrm{UF}_{\mathrm{K}}$ is the standard normal distribution, given level of significance $\alpha$, if $\mathrm{UF}_{\mathrm{K}}>\mathrm{U}_{\alpha / 2}$, which indicated the sequence trend. The time series $\mathrm{X}$ is arranged in reverse order, and subsequently calculated according to the Eq. 6.

$$
\left\{\begin{array}{l}
\mathrm{UB}_{\mathrm{K}}=-\mathrm{UF}_{\mathrm{K}} \\
k=n+1-k
\end{array}(k=1,2, \ldots, n)\right.
$$

The trend of sequence $\mathrm{X}$ can be further analysed by $\mathrm{UF}_{\mathrm{K}}$ and $\mathrm{UB}_{\mathrm{K}}$ presented in Eq. 7. If $\mathrm{UF}_{\mathrm{K}}>0$, the sequence is increasing, while, if $\mathrm{UF}_{\mathrm{K}}<0$, the sequence is decreasing. The mutation time can also be determined and the mutation region is pointed out. In this regard, exceeding the critical line suggest that the trend of rise or fall is significant. If the 2 curves of $\mathrm{UF}_{\mathrm{K}}$ and $\mathrm{UB}_{\mathrm{K}}$ intersect, and the intersection point is between the critical straight lines, then the starting point of the mutation is the corresponding moment of the intersection point ${ }^{38}$. 
Precipitation ranks analysis. According to the daily precipitation in the national standard, the precipitation grade is divided into four categories including the light rain (when the daily precipitation is $0.1-9.9 \mathrm{~mm}$ ), the moderate rain (when the daily precipitation is $10-24.9 \mathrm{~mm}$ ), the heavy rain (refers to the daily precipitation of $25-50 \mathrm{~mm}$ ), the torrential rain (refers to the daily precipitation $\geq 50 \mathrm{~mm}$ ).

In order to comprehensively evaluate the variation characteristics of precipitation in the study area, this research introduces two indicators including the precipitation occurrence rate and the precipitation contribution rate. The precipitation occurrence rate refers to the proportion of occurrences of various precipitation events, in a certain classification. The precipitation contribution rate is defined as the ratio of precipitation to the total precipitation, in a certain classification.

The wavelet analysis method and the probability density function. The wavelet analysis method has multiple modes and in this study the Morlet transform analysis has been used to analyse the data ${ }^{39}$.

The probability density function (PDF) is a function to describe the probability that the output value of a continuous random variable is near a certain point ${ }^{40}$. In this research, the PDF is adopted to analyse the probability distribution of rainfall in the Qinba Mountain area.

Spatial interpolation. During recent years, various spatial interpolation methods have been used to investigate the spatial distribution of the precipitation and the meteorological variables. The spatial interpolation was performed using the inverse distance weighted (IDW) interpolation ${ }^{41}$. The selected method for the spatial interpolation and the spatial resolution of the meteorological stations could influence the spatial pattern of precipitation. Based on our finding, the inverse distance weighting (IDW) method provided the lowest mean error, among the three common interpolation methods (i.e. the spline, the ordinary kriging, and the inverse distance weighting), thus the IDW form ArcGIS was applied to describe the spatial variability of precipitation and meteorological variables in the present study ${ }^{42}$.

Received: 9 July 2019; Accepted: 7 January 2020;

Published: 22 January 2020

\section{References}

1. Fan, X. H. \& Wang, M. B. Change trends of air temperature and precipitation over Shanxi Province, China. Theo Appl Climatol. 103(3-4), 519-531 (2011)

2. Yi, X., Li, G. \& Yin, Y. Spatio-temporal variation of precipitation in the Three-River Headwater Region from 1961 to 2010. J Geogr Sci. 23(3), 447-464 (2013).

3. Zhang, M., Chen, Y., Shen, Y. \& Li, Y. Changes of precipitation extremes in arid Central Asia. Quaternint 2017, 16-27 (2017)

4. Wang, H., Chen, Y. \& Chen, Z. Spatial distribution and temporal trends of mean precipitation and extremes in the arid region, northwest of China, during 1960-2010. Hydrol Process Rocess. 27(12), 1807-1818 (2013).

5. Wang, W. et al. Spatial and temporal characteristics of changes in precipitation during 1957-2007 in the Haihe River basin, China. Stoch EnvNV Res Risk A. 25(7), 881-895 (2011).

6. Liu, Q., Yang, Z. \& Cui, B. Spatial and temporal variability of annual precipitation during 1961-2006 in Yellow River Basin, China. J Hydrol 361(3), 330-338 (2008).

7. Gemmer, M., Jiang, T., Su, B. \& Kundzewicz, Z. W. Seasonal precipitation changes in the wet season and their influence on flood/ drought hazards in the Yangtze River Basin, China. Quaternint. 186(1), 12-21 (2008).

8. Jiang, T., Su, B. \& Hartmann, H. Temporal and spatial trends of precipitation and river flow in the Yangtze River Basin, 1961-2000. Geomorphology 85(3), 143-154 (2007).

9. Kumar, N. \& Jaswal, A. K. Historical temporal variation in precipitation over Western Himalayan Region: 1857-2006. J Mt Sci-Engl. 13(4), 672 (2016)

10. Malygina, N., Papina, T., Kononova, N. \& Barlyaeva, T. Influence of atmospheric circulation on precipitation in Altai Mountains. J Mt Sci-Engl. 14(1), 46-59 (2017).

11. Liu, J. \& Chen, R. Discriminating types of precipitation in Qilian Mountains, Tibetan Plateau. J Hydrol. 5, 20-32 (2016).

12. Wang, S., Zhang, M., Wang, B., Sun, M. \& Li, X. Recent changes in daily extremes of temperature and precipitation over the western Tibetan Plateau, 1973-2011. Quatern Int. 313, 110-117 (2013).

13. Naresh, K. \& Jaswal, Ashokkumar Historical temporal variation in precipitation over western himalayan region:1857-2006. J. Mt. Sci. 13(4), 672-681 (2016).

14. Zhang, K. et al. Spatial distribution and temporal trends in precipitation extremes over the Hengduan Mountains region, China, from 1961 to 2012. Quaternary International. 349, $346 \mathrm{e} 356$ (2014).

15. Liu, J. \& Chen, R. Discriminating types of precipitation in Qilian Mountains, Tibetan Plateau. Journal of Hydrology: Regional Studies 5, 20-32 (2016)

16. Malygina, N., Papina, T., Kononova, N. \& Barlyaeva, T. Influence of atmospheric circulation on precipitation in altai mountains. J. Mt. Sci. 14(1), 46-59 (2017).

17. Nina, K. Kononova et al. Effects of atmospheric circulation on summertime precipitation variability and glacier mass balance over the Tuyuksu Glacier in Tianshan Mountains,Kazakhstan. J Arid Land. 7(5), 687-695 (2015).

18. Qi, W. W. et al. A topographical model for precipitation pattern in the Tibetan Plateau. J Mt Sci-Engl. 13(5), 763-773 (2016).

19. Wang, Q. X., Fan, X. H., Qin, Z. D. \& Wang, M. B. Change trends of temperature and precipitation in the Loess Plateau Region of China, 1961-2010. Global Planet Change. 92, 138-147 (2012).

20. Ying, W., Wensheng, W. \& Guoqing, W. Detecting Variation Trends of Temperature and Precipitation for the Dadu River Basin, China [J]. Adv Meteorol. 2016, 1-11 (2016).

21. Salnikov, V., Turulina, G., Polyakova, S., Moldahmetov, M. \& Mahmudova, L. Climatic variations of general atmospheric circulation, precipitation and river flow of the territory of Kazakhstan. Sciences in Cold and Arid Regions 5(1), 0109-0113 (2013).

22. Qiang, F. et al. Estimation of areal precipitation in the Qilian Mountains based on a gridded dataset since 1961. J Geogr Sci 26(1), 59-69 (2016)

23. New, M., Todd, M., Hulme, M. \& Jones, P. Precipitation measurements and trends in the twentieth century. Int J Climatol 21(15), $1889-1922(2001)$.

24. Zhou, B. J., Liang, C., Zhao, P. \& Dai, Q. Analysis of Precipitation Extremes in the Source Region of the Yangtze River during 1960-2016. Water 10, 1691 (2018).

25. Wan, G., Yang, M., Liu, Z., Wang, X. \& Liang, X. The precipitation variations in the qinghai-xizang (Tibetan) plateau during 19612015. Atmosphere 8(5), 80 (2017). 
26. Shi, P., Kong, F. \& Fang, J. Spatio-temporal patterns of china decadal storm rainfall. Sci. Geogr. Sin. 34,1281-1290 (2014).

27. Peng, Y. F. et al. Spatiotemporal Variability in Extreme Precipitation in China from Observations and Projections. water. 10(8), 1089 (2018).

28. Zhang, Y. et al. Impact of projected climate change on the hydrology in the headwaters of the Yellow River basin. Hydrol. Process. 29, 4379-4397 (2015).

29. You, Q. et al. Changes in daily climate extremes in China and their connection to the large scale atmospheric circulation during 1961-2003. Climate Dynamics 36(11-12), 2399-2417(2011).

30. Yang, B. et al. Spatiotemporal characteristics of precipitation extremes in the qinba Mountain region during 1961-2011. Research of soil and water conservation.21.1 (in chinese) (2014).

31. Ronglu, G. et al. Interdecadal changes in the asymmetric impacts of ENSO on wintertime rainfall over China and atmospheric circulations over western North Pacific. Climate Dynamics (2018).

32. Zhou, B. et al. Analysis of Precipitation Extremes in the Source Region of the Yangtze River during 1960-2016. Water. 10, 1691,2018; https://doi.org/10.3390/w10111691

33. Zhang, Q. et al. Changing properties of precipitation concentration in the pearl river basin, china. Stoch Env Res. Risk A. 23(3), 377-385 (2009).

34. Zhang, Q., Singh, V. P., Li, J. \& Chen, X. Analysis of the periods of maximum consecutive wet days in china. J. Geophys Res. 116(D23) (2011).

35. Dong, S. I., Hai-ming, X. U., Min, W. E. N. \& Jin-hai, H. E. Analysis of the westward extension of western pacific subtropical high during a heavy rain period over southern China in June 2005. J. Trop. Meteor 24(2), 169-175 (2008).

36. Shi, H., Li, T., Wei, J., Fu, W. \& Wang, G. Spatial and temporal characteristics of precipitation over the three-river headwaters region during 1961-2014. J Hydrol 6, 52-65 (2016).

37. Zhai, P., Zhang, X., Wan, H. \& Pan, X. Trends in total precipitation and frequency of daily precipitation extremes over China. J Climate 18(7), 1096-1108 (2005).

38. Degefu, M. A. \& Bewket, W. Variability and trends in rainfall amount and extreme event indices in the Omo-Ghibe River Basin, Ethiopia. Reg Environ Change. 14(2), 799-810 (2014).

39. Torrence, C. \& Compo, G. P. A practical guide to wavelet analysis. B AM Meteorol Soc 79, 61-78 (1998).

40. Yuguo, D. et al. Advances in Theory and Application of Climatic Probability Distribution [J]. Meteorological Science and Technology, 37(3): 257-262 (in Chinese) (2009).

41. Yue, S. \& Wang, C. Y. The Mann-Kendall test modified by effective sample size to detect trend in serially correlated hydrological series. Water Resour Manag. 18(3) 201-218, (2004).

42. Chu, J., Xia, J., Xu, C., Li, L. \& Wang, Z. Spatial and temporal variability of daily precipitation in Haihe River basin, 1958-2007. J Geogr Sci. 20(2), 248-260 (2010).

\section{Acknowledgements}

This work was supported by the National Natural Science Foundation of China (Grant No. 41271045).

\section{Author contributions}

Y.Z. organized and wrote the manuscript. C.L. contributed to discussing the results. All authors reviewed the manuscript.

\section{Competing interests}

The authors declare no competing interests.

\section{Additional information}

Correspondence and requests for materials should be addressed to C.L.

Reprints and permissions information is available at www.nature.com/reprints.

Publisher's note Springer Nature remains neutral with regard to jurisdictional claims in published maps and institutional affiliations.

Open Access This article is licensed under a Creative Commons Attribution 4.0 International License, which permits use, sharing, adaptation, distribution and reproduction in any medium or format, as long as you give appropriate credit to the original author(s) and the source, provide a link to the Creative Commons license, and indicate if changes were made. The images or other third party material in this article are included in the article's Creative Commons license, unless indicated otherwise in a credit line to the material. If material is not included in the article's Creative Commons license and your intended use is not permitted by statutory regulation or exceeds the permitted use, you will need to obtain permission directly from the copyright holder. To view a copy of this license, visit http://creativecommons.org/licenses/by/4.0/.

(C) The Author(s) 2020, corrected publication 2021 